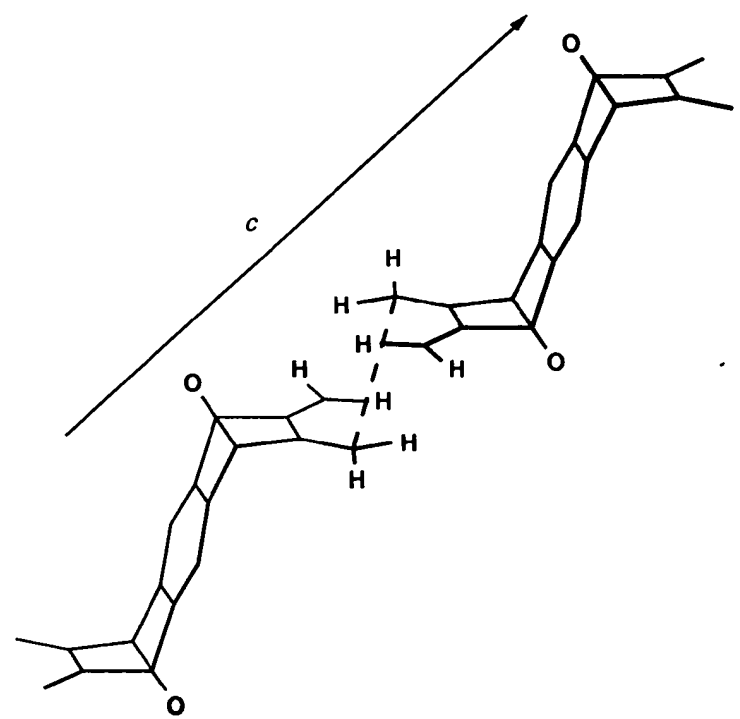

Fig. 3. Line drawing of a pair of lattice-translated molecules (6).

mean planes are 125 and $123^{\circ}$ respectively, and that between the $\mathrm{C}(1)-\mathrm{C}(2)-\mathrm{C}(3)-\mathrm{C}(4)$ and $\mathrm{C}(1)-$ $\mathrm{C}(4)-\mathrm{C}(4 a)-\mathrm{C}(9 a)$ mean planes is $112^{\circ}$. The $\mathrm{C}(1)-\mathrm{O}(1)-\mathrm{C}(4)$ plane is canted further away from the mean plane of the aromatic ring by a further $3^{\circ}$. These dihedral angles are similar to those observed in the syn isomer (Kohnke, Mathias, Stoddart, Slawin, Watts \& Williams, 1990) and in other 1,4:5,8-diepoxy-1,4,5,8-tetrahydroanthracenes (Kohnke, Stoddart, Slawin \& Williams, 1988a,b). The tilt of the diene units towards the endo faces is only a modest $2^{\circ}$ and is probably not significant (Pinkerton, Schwarzenbach, Stibbard, Carrupt \& Vogel, 1983).
The only notable intermolecular interaction (Fig. 3) is a chain of weak diene-diene interactions between lattice-translated molecules in the crystallographic c direction. The interplanar separation is $3.00 \AA$ with the shortest carbon-carbon distance being $3.48 \AA$ between $\mathrm{C}(11)$ and $\mathrm{C}\left(11^{\prime}\right)$.

We thank the Ministry of Defence and the Science and Engineering, and Agricultural and Food Research Councils in the United Kingdom, and the University of Messina in Italy, for financial support.

\section{References}

Chiba, T., Kenny, P. W. \& Miller, L. L. (1987). J. Org. Chem. 52, 4327-4331.

International Tables for X-ray Crystallography (1974). Vol. IV. Birmingham: Kynoch Press. (Present distributor Kluwer Academic Publishers, Dordrecht.)

Kohnke, F. H., Mathias, J. P., Stoddart, J. F., Slawin, A. M. Z., Watts, D. J. \& Williams, D. J. (1990). Acta Cryst. C46, $1046-1049$

Kohnke, F. H., Mathias, J. P., Stoddart, J. F., Slawin, A. M. Z. \& Williams, D. J. (1990). Acta Cryst. C46, 1043-1046.

Kohnke, F. H. \& Stoddart, J. F., Slawin, A. M. Z. \& Williams, D. J. (1988a). Acta Cryst. C44, 738-740.

KoHNke, F. H. \& Stoddart, J. F., Slawin, A. M. Z. \& Williams, D. J. (1988b). Acta Cryst. C44, 742-745.

Mahaim, C., Carrupt, P.-A., Hagenbuch, J.-P., Florey, A. \& Vogel, P. (1980). Helv. Chim. Acta, 63, 1149-1157.

Pinkerton, A. A., Schwarzenbach, D., Stibbard, J. H. A., Carrupt, P.-A. \& Vogel, P. (1983). J. Am. Chem. Soc. 103, 2095-2096.

SHELDRICK, G. M. (1983). SHELXTL, revision 4.0, January 1983. An Integrated System for Solving, Refining and Displaying Crystal Structures from Diffraction Data. Univ. of Göttingen, Federal Republic of Germany.

Thomas, A. D. \& Miller, L. L. (1986). J. Org. Chem. 51, $4160-4169$.

Acta Cryst. (1990). C46, 1051-1053

\title{
Structure of Ethyl 1-Cyanomethyl-5-methoxy-3-phenylindole-2-carboxylate
}

\author{
By T. N. Chandrakantha, K. A. Nirmala and Puttaraja \\ Department of Physics, Bangalore University, Bangalore-560 056, India \\ AND M. NeThaJI* \\ Department of Crystallography and Biophysics, Madras University, Madras-600 025, India
}

(Received 30 May 1989; accepted 22 August 1989)

\begin{abstract}
C}_{20} \mathrm{H}_{18} \mathrm{~N}_{2} \mathrm{O}_{3}, M_{r}=334 \cdot 38$, orthorhombic, Pbca, $a=7 \cdot 179$ (3), $b=33.014$ (3), $c=14.847$ (1) $\AA$, $V=3518 \cdot 85 \AA^{3}, \quad Z=8, \quad D_{x}=1 \cdot 262, \quad D_{m}=$

\footnotetext{
* Present address: Department of Inorganic and Physical Chemistry, Indian Institute of Science, Bangalore-560 012, India.
}

0108-2701/90/061051-03\$03.00
$1.263 \mathrm{Mg} \mathrm{m}^{-3}, \lambda(\mathrm{Cu} K \alpha)=1.5418 \AA, \mu(\mathrm{Cu} K \alpha)=$ $0.62 \mathrm{~mm}^{-1}, F(000)=1408, T=300 \mathrm{~K}$. Final $R=$ 0.041 for 1713 observed reflections. The indole ring system is planar with the methoxy group coplanar with the rings. The phenyl ring connected to the indole moiety is rotated about the $\mathrm{C}(3)-\mathrm{C}(10)$ bond

(C) 1990 International Union of Crystallography 
by $53 \cdot 1(3)^{\circ}$. The $\mathrm{C}-\mathrm{C} \equiv \mathrm{N}$ chain is linear and makes a dihedral angle of $77.9(3)^{\circ}$ with the mean plane of the indole ring. The mean plane of the carboxyl group makes a dihedral angle of $25.4(3)^{\circ}$ with the indole moiety.

Introduction. The title compound (I) belongs to the family of indole derivatives. Interest in these compounds is increasing with the realization of their role in obtaining pharmacologically active compounds of the type 1,2,3,4-tetrahydropiperazino[1,2-a]indoles and diazepino[1,2-a]indoles which are found to possess CNS depressant (Yamamoto, Inaba, Okamoto, Hirohashi, Ishizumi, Yamamoto, Maruyama, Mori \& Kabayashi, 1974), psychotropic (Grinev, Trofimkin, Lomanova, Andreeva \& Mashkovskii, 1978), antidepressant (Grinev, Shredov, Krichevskii, Romanova, Altukova, Kurilo, Andreeva, Golovina \& Mashkovskii, 1984), antihypertensive (Merk, 1974) and muscle relaxant (Hendi \& Basangoudar, 1981) properties.

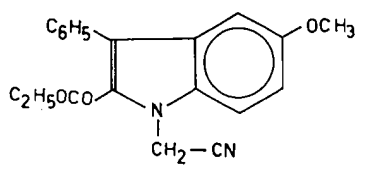

(I)

The title compound is the condensation product of ethyl 5-methoxy-3-phenylindole-2-carboxylate and chloroacetonitrile in the presence of sodium hydride. This compound can be effectively converted into 8methoxy-10-phenyl-1,2,3,4-tetrahydropyrazino[1,2-a]indole which exhibits marked CNS depressant and muscle relaxant activities (Hendi, 1977). A study was undertaken to establish the structure and the connectivity in the solid state unambiguously and forms part of the investigations of some pharmacologically important indoles and their precursors.

Experimental. Colorless transparent crystals were grown by diffusion of hexane into benzene solution, crystal of size $0.2 \times 0.12 \times 0.1 \mathrm{~mm}$ was mounted on Enraf-Nonius CAD-4 diffractometer, $\omega / 2 \theta$ scan, cell dimensions were from least-squares refinement of 18 centered reflections in the range 10 to $25^{\circ}$, density measurements by flotation technique, intensity data were collected using $\mathrm{Cu} K \alpha$ radiation, to a maximum $2 \theta=120^{\circ}$, three standard reflections ( $1 \overline{1} 3,080$ and $1 \overline{2} 4)$ monitored after every 250 reflections, $<5 \%$ intensity variation, a total of 2604 independent reflections $(h 0-9, k 0-36, l 0-16)$ of which 1713 reflections with $I \geq 3 \sigma(I)$ were considered observed, data were corrected for Lorentz-polarization effects, an empirical absorption correction based on series of $\psi$ scans applied, the minimum and maxium correction factors are 0.975 and 0.999 and the average
Table 1. Fractional coordinates $\left(\times 10^{4}\right)$ and equivalent isotropic temperature factors $\left(\AA^{2} \times 10^{4}\right)$ for non- $\mathrm{H}$ atoms (e.s.d.'s are given in parentheses)

\begin{tabular}{lrrrr} 
& $x$ & $y$ & \multicolumn{1}{c}{$z$} & \multicolumn{1}{c}{$U_{\text {eq }}{ }^{*}$} \\
$\mathrm{~N}(1)$ & $7163(3)$ & $1219(1)$ & $-1051(1)$ & $588(8)$ \\
$\mathrm{C}(2)$ & $6100(4)$ & $1411(1)$ & $-393(2)$ & $523(9)$ \\
$\mathrm{C}(3)$ & $4687(3)$ & $1161(1)$ & $-125(2)$ & $475(8)$ \\
$\mathrm{C}(4)$ & $3803(4)$ & $439(1)$ & $-677(2)$ & $514(9)$ \\
$\mathrm{C}(5)$ & $4369(4)$ & $136(1)$ & $-1256(2)$ & $562(9)$ \\
$\mathrm{C}(6)$ & $5938(5)$ & $184(1)$ & $-1811(2)$ & $655(11)$ \\
$\mathrm{C}(7)$ & $6959(4)$ & $538(1)$ & $-1798(2)$ & $633(1)$ \\
$\mathrm{C}(8)$ & $6407(4)$ & $844(1)$ & $-1210(2)$ & $546(9)$ \\
$\mathrm{C}(9)$ & $4858(4)$ & $796(1)$ & $-647(2)$ & $483(9)$ \\
$\mathrm{C}(10)$ & $3168(3)$ & $1240(1)$ & $523(2)$ & $448(8)$ \\
$\mathrm{C}(11)$ & $2055(4)$ & $1582(1)$ & $452(2)$ & $561(9)$ \\
$\mathrm{C}(12)$ & $641(4)$ & $1651(1)$ & $1061(2)$ & $687(1)$ \\
$\mathrm{C}(13)$ & $310(4)$ & $1379(1)$ & $1748(2)$ & $731(12)$ \\
$\mathrm{C}(14)$ & $1373(4)$ & $1038(1)$ & $1820(2)$ & $664(11)$ \\
$\mathrm{C}(15)$ & $2795(4)$ & $967(1)$ & $1212(2)$ & $541(9)$ \\
$\mathrm{O}(16)$ & $3499(3)$ & $-230(1)$ & $-1354(1)$ & $693(7)$ \\
$\mathrm{C}(17)$ & $1913(5)$ & $-306(1)$ & $-805(2)$ & $778(12)$ \\
$\mathrm{C}(18)$ & $8827(4)$ & $1369(1)$ & $-1499(2)$ & $677(11)$ \\
$\mathrm{C}(19)$ & $8378(4)$ & $1551(1)$ & $-2374(2)$ & $613(10)$ \\
$\mathrm{N}(20)$ & $7985(4)$ & $1686(1)$ & $-3048(2)$ & $839(12)$ \\
$\mathrm{C}(21)$ & $6544(4)$ & $1831(1)$ & $-125(2)$ & $603(10)$ \\
$\mathrm{O}(22)$ & $7369(4)$ & $2066(1)$ & $-599(2)$ & $937(10)$ \\
$\mathrm{O}(23)$ & $5914(3)$ & $1918(0)$ & $685(1)$ & $616(7)$ \\
$\mathrm{C}(24)$ & $6100(4)$ & $2337(1)$ & $985(2)$ & $725(11)$ \\
$\mathrm{C}(25)$ & $5230(7)$ & $2364(1)$ & $1890(2)$ & $1011(16)$ \\
& & & &
\end{tabular}

* The temperature factor is of the form: $U_{\text {eq }}=\frac{1}{3} \sum_{i} \sum_{j} U_{i} a_{i}^{*} a_{j}^{*} \mathbf{a}_{i} \mathbf{a}_{j}$.

correction factor 0.986 . The structure was solved by direct methods using the MULTAN80 (Main, Fiske, Hull, Lessinger, Germain, Declercq \& Woolfson, 1980) program, all the $\mathrm{H}$ atoms were located from the difference Fourier map, full-matrix least-squares refinement (on $F$ ) with anisotropic thermal parameters for non- $\mathrm{H}$ atoms and isotropic for $\mathrm{H}$ atoms using the SHELX76 (Sheldrick, 1976) program. Final $R=0.041$ and $w R=0.049, \quad w=\left[\sigma^{2}(F)+\right.$ $\left.|g| F^{2}\right]^{-1}, g=0.0013, \sigma$ 's based on counting statistics, the refinement terminated when shift/e.s.d for non- $\mathrm{H}$ atoms was less than $0 \cdot 2$, the minimum and maximum residual electron densities in the final difference Fourier map are -0.17 and 0.12 e $\AA^{-3}$. The final positional parameters of the non-H atoms with $U_{\text {eq }}$ are given in Table $1{ }^{*}$ Scattering factors were from $S H E L X$.

Discussion. A view of the molecule with bond lengths and angles is shown in Fig. 1. The ORTEP (Johnson, 1965) plot of the molecule with $50 \%$ probability ellipsoids is shown in Fig. 2. The indole moiety is planar with the methoxy group lying in the plane. The phenyl ring connected to the indole ring is rotated through an angle of $53.1^{\circ}$ about the

\footnotetext{
* Lists of structure factors, anisotropic thermal parameters and $\mathbf{H}$-atom parameters, and a stereo packing diagram of the molecule viewed down the $a$ axis have been deposited with the British Library Document Supply Centre as Supplementary Publication No. SUP 52540 (12 pp.). Copies may be obtained through The Technical Editor, International Union of Crystallography, 5 Abbey Square, Chester CH1 2HU, England.
} 
$\mathrm{C}(3)-\mathrm{C}(10)$ bond. The $\mathrm{C}-\mathrm{C} \equiv \mathrm{N}$ chain is almost linear, the angle $\mathrm{C}(18)-\mathrm{C}(19)-\mathrm{N}(20)$ being $178.1(3)^{\circ}$, and makes a dihedral angle of $77.8(3)^{\circ}$ with the mean plane of the indole rings. The ester moiety is syn to $\mathrm{C}=\mathrm{O}$ about the $\mathrm{C}-\mathrm{O}$ bond, the torsion angle $\mathrm{C}(24)-\mathrm{O}(23)-\mathrm{C}(21)-\mathrm{O}(22)$ is $5 \cdot 5(5)^{\circ}$.

The bond lengths and angles in the phenyl ring are all normal. In the five-membered ring the two $\mathrm{C}-\mathrm{N}$ bonds are almost equal. The bond length $\mathrm{C}(2)-\mathrm{C}(3)$ of 1.368 (4) $\AA$ is shorter while the $\mathrm{C}(3)-\mathrm{C}(9)$ bond is longer than the normal aromatic $\mathrm{C}-\mathrm{C}$ bond. The data available on bond lengths in indole rings in various structures (Falkenberg \& Carlstrom, 1971; Vijayalakshmi \& Srinivasan, 1975; Roychowdhuri \& Basak, 1975; Chandrashekar \& Pattabhi, 1980), including the present study, indicate that the $\mathrm{C}(3)$ $\mathrm{C}(9)$ bond is longer than the standard aromatic $\mathrm{C}-\mathrm{C}$ bond of $1.395 \AA$. The bond angle $\mathrm{C}(4)-$

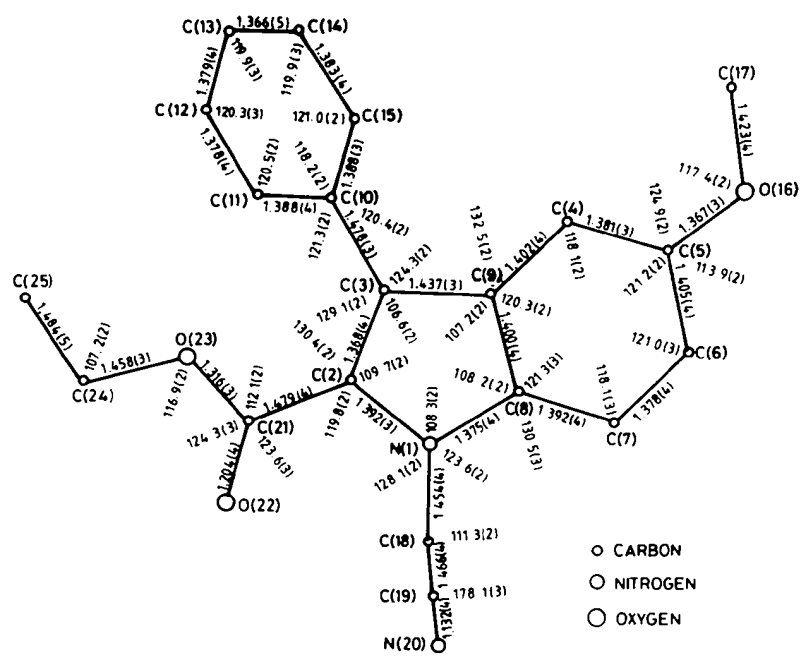

Fig. 1. A view of the molecule with bond lengths $(\AA)$ and bond angles $\left({ }^{\circ}\right)$. The e.s.d.'s are in parentheses.

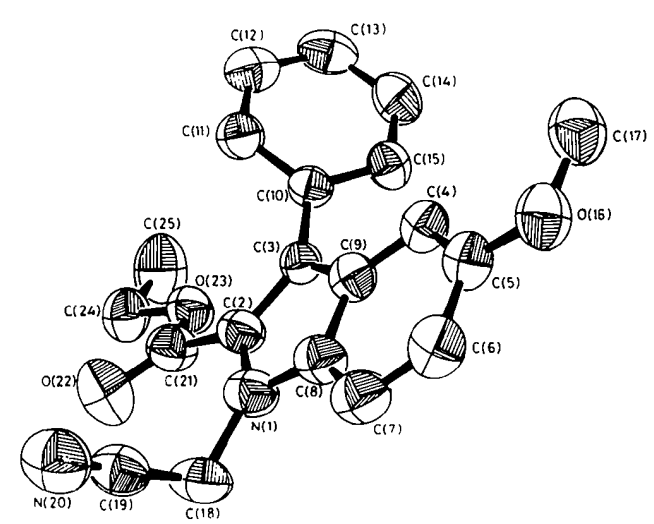

Fig. 2. A view of the molecule with $50 \%$ probability thermal ellipsoids.
$\mathrm{C}(5)-\mathrm{O}(16)$ is larger than $\mathrm{C}(6)-\mathrm{C}(5)-\mathrm{O}(16)$ by $11^{\circ}$ and similar results have been observed in related compounds containing methoxy groups (Wakahara, Fujiwara \& Tomita, 1972; Falkenberg \& Carlstrom, 1971; Sakaki, Wakahara, Fujiwara \& Tomita, 1975). This may be due to cis orientation of the $C(4)-C(5)$ and $\mathrm{C}(17)-\mathrm{O}(16)$ bonds causing the bond angle to be larger because of repulsion between $\mathrm{C}(4)$ and C(17) (Sakaki, Sogo, Wakahara, Kanai, Fujiwara \& Tomita, 1976).

There are no intra- or intermolecular hydrogen bonds and the structure is stabilized mainly by van der Waals interactions.

The authors wish to thank Professor K. Venkatesan, Department of Organic Chemistry, Indian Institute of Science, Bangalore, for his encouragement and interest in the work and Dr Vasantha Pattabhi, Department of Crystallography and Biophysics, Madras University, Madras, for collecting the data. They also thank Dr A. Y. Merwade for providing the powder sample. One of the authors (TNC) thanks the University Grants Commission, New Delhi, India, for the fellowship.

\section{References}

Chandrashekar, K. \& Pattabh, V. (1980). Acta Cryst. B36, $1165-1169$.

FalkenberG, G. \& Carlstrom, D. (1971). Acta Cryst. B27, $411-418$.

Grinev, A. N., Shredov, V. I., Krichevskit, E. S., Romanova, O. B., Altukova, L. B., Kurilo, G. N., Andreeva, N. I., Golovina, S. M. \& MashKovskiI, M. D. (1984). Chem. Abstr. 101, 23433.

Grinev, A. N., Trofimkin, Yu. I., Lomanova, E. V., Andreeva, N. I. \& MaShkovskil, M. D. (1978). Chem. Abstr. 89, 163546.

Hendi, S. B. (1977). PhD Thesis, Karnatak Univ., Dharwad, India.

Hendi, S. B. \& Basangoudar, L. D. (1981). Indian J. Chem. 20B, 285.

JOHNSON, C. K. (1965). ORTEP. Report ORNL-3794. Oak Ridge National Laboratory, Tennessee, USA.

Main, P., Fiske, S. J., Hull, S. E., Lessinger, L., Germain, G., DeClercQ, J.-P. \& WoOlfson, M. M. (1980). A System of Computer Programs for the Automatic Solution of Crystal Structures from X-ray Diffraction Data. Univs. of York, England, and Louvain, Belgium.

MERK (1974). Chem. Abstr. 80, 27298.

RoYchOWdHURI, P. \& BaSAK, B. S. (1975). Acta Cryst. B31, $1559-1563$.

Sakaki, T., Sogo, A., Wakahara, A., Kanai, T., Fujiwara, T. \& TOMita, K. (1976). Acta Cryst. B32, 3235-3242.

SaKaki, T., WaKahara, A., Fujiwara, T. \& Tomita, K. (1975). Bull. Chem. Soc. Jpn, 48, 536-540.

SHELDRICK, G. M. (1976). SHELX76. Program for crystal structure determination. Univ. of Cambridge, England.

Vijayalakshmi, B. K. \& Srinivasan, R. (1975). Acta Cryst. B31, 999-1003.

Wakahara, A., Fujiwara, T. \& Tomita, K. (1972). Chem. Lett. pp. 1139-1142.

Yamamoto, H., Inaba, S., OKamoto, T., Hirohashi, T., IshizUMI, K., Yamamoto, M., MarUYama, I., MORI, K. \& Kabayashi, T. (1974). Chem. Abstr. 81, 63673. 